\title{
Advocating a need for suitable breeding approaches to boost Integrated Pest Management: A European perspective
}

Jay Ram Lamichhane ${ }^{1 *}$, Edward Arseniuk², Piet Boonekamp³ ${ }^{3}$, Jerzy Czembor², Veronique Decroocq ${ }^{4}$, Jérome Enjalbert ${ }^{5}$, Maria R. Finckh ${ }^{6}$, Małgorzata Korbin', Mati Koppel ${ }^{8}$, Per Kudsk $^{9}$, Akos Mesterhazy ${ }^{10}$, Danuta Sosnowska ${ }^{11}$, Ewa Zimnoch-Guzowska ${ }^{12}$, Antoine Messéan ${ }^{13}$

${ }^{1}$ UMR AGIR, INRA, 31326 Castanet-Tolosan, France

2Plant Breeding and Acclimatization Institute - National Research Institute, Radzikow, 05870 Błonie, Poland

${ }^{3}$ Wageningen University \& Research centre, Biointeractions and Plant Health, Droevendaalsesteeg 1, 6700 AA Wageningen, The Netherlands

${ }^{4}$ UMR BFP INRA-Université de Bordeaux, Equipe de Virologie, CS20032, 33883 Villenave d'Ornon, France

5UMR GQE - Le Moulon, INRA, Univ Paris-Sud, CNRS, AgroParisTech, Université ParisSaclay, F-91190, Gif-sur-Yvette, France

${ }^{6}$ Group ecological Plant Protection, Faculty of Organic Agricultural Sciences, University of Kassel. Norbahnhofstr. 1 a, D-37213 Witzenhausen, Germany

${ }^{7}$ Research Institute of Horticulture, Skierniewice, Poland

8Estonian Crop Research Institute, J. Aamisepa 1, 48309 Jõgeva, Estonia

${ }^{9}$ Aarhus University, Department of Agroecology, Forsoegsvej 1, 4200 Slagelse, Denmark

${ }^{10}$ Cereal Research Non-Profit Ltd, Szeged, Hungary

11Institute of Plant Protection - National Research Institute, Wladyslawa Wegorka Street. 20, 60-318 Poznań, Poland

${ }^{12}$ Plant Breeding and Acclimatization Institute - National Research Institute, Department of Potato Genetics and Parental Lines, Platanowa 19, 05-831 Młochów, Poland

13Eco-Innov Research Unit, INRA, 78850 Thiverval-Grignon, France

*Corresponding author E-mail: ذay-Ram.Lamichhane@inra.fr

Tel: +33 (0)5 612852 50; Fax: +33 (0)5 61285537

\section{Abstract}

Currently, European farmers do not have access to a sufficient number and diversity of crop species/varieties. This prevents them from designing more resilient cropping

This article has been accepted for publication and undergone full peer review but has not been through the copyediting, typesetting, pagination and proofreading process, which may lead to differences between this version and the Version of Record. Please cite this article as doi: $10.1002 / p s .4818$ 
systems to abiotic and biotic stresses. Crop diversification is a key lever to reduce pest (pathogens, animal pests and weeds) pressures at all spatial levels from fields to landscapes. In this context, plant breeding should consist of: i) increased efforts in the development of new or minor crop varieties to foster diversity of cropping systems, and ii) focus on more resilient varieties showing local adaptation. This new breeding paradigm, called here "breeding for Integrated Pest Management (IPM)", may boost IPM - through the development of cultivars with tolerance or resistance to key pests - with an ultimate goal of reducing reliance on conventional pesticides. At the same time, this paradigm has legal and practical implications for future breeding programs, including those targeting sustainable agricultural systems. By putting these issues into the context, this paper presents the key outcomes of a questionnaire survey as well as experts' views expressed during an EU workshop entitled "Breeding for IPM in sustainable agricultural systems".

Keywords: Crop diversification, decentralization, DUS, food security, minor crops, participatory plant breeding, seed legislation, sustainable agriculture 


\section{Introduction}

For effective management of crop pests (pest in sensu lato which includes animal pests, diseases and weeds), Integrated Pest Management (IPM) combines all available crop protection strategies, including non-chemical (biological, cultural, genetic, mechanical and physical) and chemical (as the last resort) measures. ${ }^{1,2}$ By prioritizing the adoption of non-chemical measures, IPM represents an important approach to sustainable and durable pest management. Unlike conventional crop protection that emphasizes resistant varieties (pre-epidemic, as prevention) and chemical treatments (during or postepidemic, as control), IPM focuses mainly on the deployment of cultivar resistance in combination with agronomic practices, especially rotations and enhancement of natural biological control, and strives to avoid the need for chemical measures.

As a preventive measure, plant genetic resources (resistant, partially-resistant or tolerant varieties) play an important role in IPM. Breeding crops suitable for specific local conditions is of paramount importance for IPM to keep the use of pesticides at a minimum level. Under the current legislation, this approach implies a need for breeding individual and, usually, genetically uniform varieties for each specific local condition. However, genetically uniform crops may not be able to fulfil the needs of IPM because of increases in climatic variation and often rapid adaptation of pest populations. Therefore, in addition to resistance (i.e. capacity of plants to prevent pest attacks and/or reduce their associated populations), a focus on crop resilience (i. e. capacity of crops to respond to a disturbance by resisting biotic and abiotic damage and recovering quickly) ${ }^{3}$ is a prerequisite for IPM and there is a need for defined traits of resilience for breeding.

Currently, private plant breeding programs are market-driven and mostly targeted towards conventional agriculture. This is not consistent with the societal demand we are 
facing today which calls for the diversification of agriculture to fit contrasting environments and to ensure sustainability.4,5 There are increasing concerns that current breeding programs do not fulfil the needs of IPM and that besides focusing on resistance genes sensu stricto, plant breeding needs to consider other agronomic traits such as complementary cultivation practices and diversification strategies within and among crops. ${ }^{6}$ This means that varieties chosen for IPM may or may not be diverse than those aimed for organic farming. While varieties bred for organic farming are partially compatible with breeding for IPM, it may not be the opposite since these two systems differ each other (Box 1). This raises questions about whether plant breeders must adopt distinct breeding programs for different environments and cultivation practices (e.g. how to breed for agricultural practices that mix different crop species in the same plot or/and the same farm) in order to boost IPM. In addition, it is not clear if conventional breeding programs are compatible with IPM measures or if they need further improvements/adaptations. Taking into account the importance of this topic, the European Research Area Network of Integrated Pest Management in Europe (ERA-NET "C-IPM; http://c-ipm.org/) organized a two and half day workshop entitled 'Breeding for IPM in sustainable agricultural systems'. The workshop was held from the $4^{\text {th }}$ to $6^{\text {th }}$ July 2016 at the Plant Breeding and Acclimatization Institute, Radzików, Poland (http://ihar.edu.pl/C-IPM_workshop.php). This paper is partly built on the major outcomes of a questionnaire survey implemented pre-workshop as well as experts' views expressed during the workshop on the issues described above and reports the results in view of the current literature.

\section{Design and analysis of the questionnaire survey on breeding for IPM}




\subsection{Questionnaire design and survey}

A questionnaire was designed in collaboration with European experts involved in the scientific committee of the workshop. The objective of the questionnaire was to collect the most relevant information concerning breeding for IPM. The questionnaire included nine questions with multiple-choice answers and provided the opportunity for the respondents to express alternative opinions (Table 1; Supplementary material S1).

The questionnaire was sent out by e-mail, five weeks before the workshop. The goal was to receive feedback from as many experts as possible throughout Europe, to learn about their views on breeding for IPM. In total, the questionnaire was sent out to 46 people from 19 European countries: Austria, Czech Republic, Denmark, Estonia, France, Germany, Greece, Hungary, Ireland, Italy, Lithuania, The Netherlands, Norway, Poland, Portugal, Spain, Sweden, Switzerland, and Turkey. The recipients were chosen based on their scientific expertise and practical experience on the topic. Feedback was requested only from those participants who were comfortable with the content of the questionnaire, meaning that they had a strong expertise to provide relevant answers to the questionnaire. A reminder was sent out to non-respondents three weeks before the workshop. All questionnaire survey materials were provided in English (Table 1).

\subsection{Face-to-face discussion during the workshop}

Fifty-seven experts from 16 European countries - including scientists, governmental officials, policy makers, company representatives and agricultural advisors - met and discussed several issues. These included: i) whether IPM calls for the development of new breeding objectives and methods, ii) if there are already ongoing R\&D programs on breeding for IPM, both at national and European level, and iii) how we can promote IPM measures by combining agronomic practices with the newly-deployed breeding 
materials. Plenary discussions held during the workshop aimed to address the issues described above.

\subsection{Data analysis and results}

For each question with multiple answers, data were expressed in percentage, which was given by the ratio between the number of responses obtained and the number of total respondents (Table 1).

Overall, we received 39 answers from 16 European countries. A summary of the analyzed responses is presented in Table 1 . Among the selectable answers there was no overall consensus among the respondents, in regard to what breeding for IPM is. Most respondents agreed that breeding targeting sustainable pest and disease resistance (69\%) and combining/adapting breeding strategies with other agronomic practices (59\%) was part of breeding for IPM (Table 1). This suggests that there was a general confusion among respondents between "breeding for sustainable resistance" and "breeding for IPM"; the former focusing on individual crop genetics to combat biotic attack whereas the latter considers the cropping system as a whole (genetics + agronomy). Depending on how the question was phrased, most respondents agreed that agronomic practices and traits need to be considered in breeding for IPM $(49 \%$ in question 1 and $87 \%$ in question 5). In contrast, only $36 \%$ of the respondents considered organic breeding as breeding for IPM (Table 1). This could be because the European experts polled were not familiar with breeding for IPM or for organic farming systems.

Some recent transnational projects (i.e. ABSTRESS, BIOEXPLOIT, SOLIBAM, COBRA, DIVERSIFOOD, Breed4Future, MULTIRES and EMPHASIS) in Europe clearly emphasize the increasing trend toward breeding for sustainable, and/or organic agricultural systems (Supplementary material S1). A number of initiatives at national levels - in France, 
Germany, Greece, Hungary, Ireland, Italy, Lithuania, Poland, Portugal, Norway and Switzerland - highlight that there is interest in breeding for low-input agricultural systems which can promote IPM (see question 3; Supplementary material S1). From the analysis of the survey, it appears that several factors need to be considered to promote breeding for IPM at the European level, including development of varieties for specific regional and site-specific conditions, minor crops, and a special focus on the enhancement of crop diversification (Table 1; Supplementary material S1).

Three strategies were advocated by most of the respondents to integrate existing breeding technologies into a wider IPM context: i) breeding for durability of resistance/tolerance (i.e. intrinsic durability and/or higher resistance variability for better $R$ gene deployment), ii) breeding for resistance in minor crops (especially those having allelopathic activity including many Brassica species); and iii) breeding for IPM including local adaptation (i.e. terroir effects, local disease pressures, positive interactions with biological control) and intra-/inter-specific mixtures or other alternative cultivation practices (i.e. intercropping ). The combination of agronomic and resistance traits was selected as a means to integrate existing breeding technologies into a wider IPM context by most respondents as well as a priority on disease resistance breeding (87\%). Factors explicitly named as important for IPM were: development of varieties with higher resistance to soil- and seed-borne pathogens to reduce the reliance on seed treatments; making plants less attractive or repellent to animal pests and more competitive or allelopathic to weeds; integration of available biochemical, physiological and genetic traits that are unfavorable for pests into practical breeding programs; a better understanding of the interactions between plants/environments/pathogens; and breeding varieties that have a reasonable level of resistance to all important diseases and pests rather than focusing on "super" resistance to only a few diseases/pests (Supplementary material 
S1). Currently, the list of recommended varieties does not usually consider varieties that have a relatively low resistance level to important diseases/pests. Growers are increasingly concerned by 'super resistance' due to issues encountered over the last decade - particularly the breakdown of major $R$ gene resistance, for example, with wheat rusts.

A clear trend from the survey is that breeding for disease resistance should be the most important priority (Table 1). However, targets of breeding for IPM R\&D programs may differ from one region to another due to local conditions (e.g. diseases are more important in humid regions while exotic insect pests could be priority problems along coastal regions as they arrive from other geographical regions). Only $31 \%$ and $28 \%$ of the respondents thought that the focus should be on intercropping of multiple species and intraspecific mixtures, respectively. Importantly, however, in the freely written replies, very specific breeding goals such as breeding for diversity, integration of the plant microbiome, resilience and several other diversity-associated traits were suggested (Supplementary material S1). Crop rotation was considered as the most important agronomic lever for IPM, followed by intercropping and intraspecific diversity (Table 1).

\section{Recommendations to boost IPM through breeding}

Based on the outcomes of the plenary sessions and subsequent discussions, the working group of European experts discussed current implementation status in breeding programs of different IPM tools in conventional, organic and low-input farming systems (Table 2). In particular, it was highlighted that while breeding has strongly focused on host genetic resistance to diseases and pests in all farming systems, although to a different extent, most IPM leverages are not still considered as breeding target in none of the three 
farming systems (Table 2). The working group also provided the following recommendations to be considered in future breeding programs to help boost IPM.

\subsection{Make the regulatory systems more favorable for IPM}

According to EU legislation, a plant variety can be commercialized only after its registration in the EU catalogue; however to be registered, it must meet the so-called DUS (distinctiveness, uniformity and stability) evaluation criteria.4,5 These standards warrant that a newly proposed variety, by a seed company, for registration has really new and distinct characteristics than the existing cultivars. Such a new variety should be fixed genetically (highly homozygous inbred lines), and therefore can be multiplied and distributed in the future without significant variations in their characteristics. The DUS precludes any genetic diversity within varieties, and therefore within fields, as they are usually seeded by single varieties. In addition, although regulations for variety registration differ among countries, often those regulations include standards known as "value for cultivation and use" (VCU) which measure agronomic performance and technical end-use quality in conventional systems. ${ }^{5,7}$ The VCU warrants that a registered variety is providing a genetic progress in productivity, quality, or disease resistance. In most cases, these performances are evaluated in multi-local experiments using conventional cropping practices (however, VCU for organic systems exist). This represents a paradox leading to a lack of suitable varieties for IPM systems: plant varieties are primarily selected and centralized across breeding stations which are often in the best growing areas and as such most modern varieties are developed for and tested in conventional cropping systems with a high input of pesticides. Testing in different environments may result in important changes in traits of importance (e.g. early 
development). ${ }^{8}$ The main bottlenecks in cropping system diversification are the number of varieties commercially available to farmers, and the lack of genetic diversity within and among varieties following their registration post-DUS. Consequently, farmers willing to adopt IPM systems are often deprived of varieties adapted to their farming systems. Indeed, over $95 \%$ of varieties used today, including those in organic agriculture, were initially bred for conventional systems. ${ }^{9}$ Because the adoption of IPM principles is mandatory in the $\mathrm{EU}^{2}$, it is important that farmers have access to adequate plant varieties that are easily adaptable to local conditions. To fit with IPM, besides good levels of resistance to reduce the need for pesticides, plant varieties must be more resilient to combined biotic and abiotic stresses, and be more adaptable to changes in pest pressure, reduced $\mathrm{N}$ input, etc. Resilience and adaptability require a certain level of functional within-crop diversity. This can be achieved through variety mixtures, diversified varieties, and intercropping. ${ }^{10}$ Thus, just increasing the number of varieties on the market does not promote IPM if those varieties were not bred for its purposes. The paradigm of breeding for resistance and genetic uniformity in breeding for IPM must be changed; however, this is more complex than just registering more varieties and will require legal changes. Until these new varieties are available, existing varieties on the market should be screened for their suitability for IPM-based production systems. In particular, a higher adaptability of a given variety to different ecological and epidemiological conditions is highly helpful for IPM purposes. ${ }^{11}$

\subsection{Decentralize the variety selection process based on participatory plant breeding programs to test for resilience in contrasting environments or cultivation practices}


Local and specific cropping/environmental conditions create micro-markets for breeders. While these micro-markets may not be realistically covered or targeted by private breeding companies, breeding varieties for specific regions is common practice. If breeders see a market for IPM varieties they will change their present selection system and focus on IPM-type selection systems. Breeders have many selection sites and demofarms across Europe and thus they would be able to decentralizing selection to a certain degree. Taking a step further by including local farmers will facilitate the move from current breeding to IPM-breeding.

Heterogeneous populations based on multiple crosses, combined with on-farm cultivation and selection, allow for the evolution of specific adaptation. This has been suggested for other forms of sustainable agricultural systems including organic breeding. ${ }^{6}$ For this to be legally and practically possible, there is a need for considerable legislative changes including the development of means that will allow for unequivocal varietal identification or alternative ways to ensure that breeders are adequately compensated for their efforts. ${ }^{5}$

Decentralization of the selection process has been proposed as an important strategy to favor selection in a targeted environment. ${ }^{12}$ However, decentralized selection on regional research stations may not be representative of on-farm environments and management in the long-term when considering changing climate and pest populations. Therefore, it will be desirable to select more resilient varieties which can adapt to different environments as well as to environmental changes rather than focusing on one cultivar per environment. To address this problem, participatory plant breeding (PPB) strategies ${ }^{10}$ have to be considered as it reduces differences between selection sites and the target environments. ${ }^{12,13}$ PPB considers both farmer's specific knowledge about 
environmental conditions and plant traits that are adapted to local situations. One of the major drawbacks of conventional breeding lies in the fact that the need for specific traits (both agronomic and quality) for different environments and management practices has been poorly considered in the official varietal registration process. However, the situation has evolved recently in many countries, especially for the registration of varieties adapted to organic farming. Because agricultural systems that aim to promote IPM face different challenges that are not present in conventional systems (e.g. more heterogeneous environmental conditions, small market size resulting in a lack of interest by the private seed sector), it is essential that PPB strategies that address such issues are adopted. ${ }^{14}$ As highlighted in a previous study, ${ }^{6}$ a project with the involvement of farmers can have far greater durability than a project tied to a particular grant or funding source without farmers. PPB promotes a sustainable process of varietal innovation, not necessarily leading to newly fixed varieties, but rather to well-adapted heterogeneous populations for specific farms or regions which can continue to evolve.

\subsection{Focus on breeding for crop diversification}

Although mixed cropping systems provide several benefits they are not much adopted by farmers due to technical difficulties related to crop management (e.g. sowing and harvest). In addition, no specific co-breeding programs to promote these systems have been developed yet. An example of pre-breeding efforts for companion crops was the EU project OSCAR which screened wheat germplasm for suitability to be grown with an associated living mulch. The goal here was to increase integration of living mulches, with an explicit focus on disease management while increasing system sustainability. ${ }^{14}$ In addition to the requirement of readjusting breeding targets, we should think about the genetic structure of varieties given that crop lines or hybrids are not necessarily the best 
genetic solution to maximize the productivity under mixed cropping systems. Indeed, many studies have shown varietal mixtures to be an option. $5,10,16,17$

The high level of geographic specialization of agricultural systems (e.g. geographic separation between livestock and arable production) that has occurred in recent decades has led to a significant worldwide reduction in the number of crops available for cropping systems. This contributes to the homogeneity of agricultural products ${ }^{18}$ thereby leading to a shift in the global food supply chain, under the influence of industrial, financial and political forces. As a result, farmers focused on high-yielding and, in the short term, the most profitable crop varieties, which led to an increased adoption of short rotations or monoculture practices. ${ }^{19}$ One consequence is the dominance of few genetic crop lines in modern agriculture. Genetic uniformity is one of the greatest hazards leading to cropping system vulnerability and homogeneity resulting in yield stagnation, ${ }^{20}$ recurrent problems related to host resistance breakdown, ${ }^{21-23}$ and the development of pest resistance to pesticides. $^{1}$

To address these challenges and develop truly sustainable agriculture, several recent studies have emphasized the need for greater diversity in agriculture.9,24,25 Crop diversification can occur at different levels including the farming system, the cooperative or at the landscape level. Crop diversification should also include considerations for new cropping systems in space (inter- or mixed-cropping, landscape planning) and time (rotation). ${ }^{10,26,27}$

Nevertheless, the limited range of market-driven crop varieties is a major obstacle to crop diversification. It hinders certain beneficial practices as, for example, there is a lack of choice of varieties that may be adapted to multiple cropping or intercropping strategies. ${ }^{18}$ Even for those crops that are widely grown and for which breeding investment is 
significant, breeding criteria are still driven by the needs of conventional cropping systems mainly targeting agronomic performances, including yield potential, technological characteristics to meet requirements of downstream supply chains, and, to a lesser extent, pest resistance. ${ }^{28}$ Adaptation of varieties to different conditions can be costly within traditional breeding systems. Participatory methods involving farmers and employing modern information technology, to help in assessments and communication, may offer low-cost solutions. In addition, within-crop diversity buffers against environmental variance and generally leads to greater yield stability across environments. ${ }^{10,29-33}$

Recently, "greening" became part of the EU agricultural policies (http://ec.europa.eu/agriculture/direct-support/greening/index en.htm). Green direct payments account for $30 \%$ of EU countries' direct payment budgets and farmers receiving an area-based payment have to adopt practices that benefit the environment and the climate. Currently they include: diversifying crops, maintaining permanent grassland and dedicating 5\% of arable land to 'ecologically beneficial elements' ('ecological focus areas'). Although the objectives of 'greening' are not to promote IPM, more diversified cropping systems, more grassland and 'ecological focus areas' could contribute to the adoption of IPM and reduce the reliance on conventional pesticides. Given the strategic role of breeding in the competitiveness of crops and their adaptation to more diversified cropping systems, there is a need to assess to what extent breeding strategies and programs should consider IPM measures. This should be done at the plant level (e.g. disease resistance) and also by considering other components of cropping systems with a special focus on crop diversification. This could be set in combination with other technical or organizational innovations such as breeding new varieties adapted to innovative technical guidelines for low input of pesticides, minimized need for irrigation, 
crop diversification by mixing varieties or species or population breeding, and new guidelines for tree pruning). Breeding approaches focused on adaptation to intercropping, above-ground versus below-ground crop-weed competition, competitiveness of minor crops, and deployment of varieties at the landscape level are promising for IPM.

Another aim could be breeding for crops that have potential for push-pull effects or that have higher allelopathic potentials against weeds. However, a low market size is an obstacle for such crops to be adopted; cultivation (and thus breeding) of minor crops needs to be justified economically. Growing a greater number of crops may require access to more machinery, storage and knowledge. It is vital that growers see a return on their investment and the end-market requirements will have a massive influence on this. If the risks outweigh the potential return then the new crop will not be adopted. Therefore, measures improving the economic attractiveness and ultimate acceptance of crops requiring less pesticides are needed. This means reducing obstacles to growing mixtures (e.g. for products intended for feed or processing); using minor crops to improve the overall ecological services of the system; and encouraging public breeders to focus on minor crops. To support such initiatives appropriate policies and adapted regulations will be required. ${ }^{5}$

While mixed farming (i.e. livestock and crops) and/or diversified cropping systems have a strong potential to reduce reliance on conventional pesticides, such cropping systems also raise major questions and challenges for breeders including how to: i) adapt assessment parameters of varieties replacing performance in pure stands with the performance in mixed stands; ii) look for optimal interaction between two (or more) coplanted species/varieties; iii) integrate or develop knowledge on plant-plant interactions 
which is helpful to design plant ideotype and trait combination; iv) optimize screening and phenotyping methods, in order to deal with their dimensionality (e.g. species (variety) $1 \mathrm{X}$ species (variety) 2 combinations); and v) adapt the spatial designs of nurseries so that assessed plant interactions reflect the real conditions occurring in farmer's fields. ${ }^{34,35}$

\subsection{Adopt new breeding techniques in IPM breeding programs}

Breeding is still strongly dominated by "the uniformity paradigm" seeking for dominant and universal plant characteristics adapted to the dominant cropping systems. From mass or genealogical selection, the breeding methods have strongly evolved, integrating now molecular tools and in vitro culture. Marker-assisted selection has evidently improved the efficiency of traditional breeding for monogenic and polygenic traits. For example, backcross assisted by markers is of special importance for the incorporation of characteristics from wild crop relatives or landraces into modern crops.5,36 Presently, genomic selection is integrated by most breeding companies to further accelerate the genetic gains in their breeding programs. Markers can also be used to assess and verify diversity in heterogeneous populations for unequivocal identification and to ensure maintenance of diversity that is difficult to assess phenotypically.

As discussed above, most breeding programs of private seed companies or public research institutes are rooted in the DUS and VCU criteria that lead respectively to the selection of i) single genotype (and ideotype) within a variety, and ii) very similar ideotypes in the registered varieties, as they are all selected for the same standardized and high input target agronomic environment. In the face of climate change and ever changing pest populations, it is not likely that a single plant genotype can fulfill all requirements of a resilient variety. These requirements may include: tolerance to limited 
or excessive water, heat or cold, and resistance to many different pests that will increase in variability with increasing climatic variation. Therefore, a trait-based breeding approach that relies on the selection of multiple and varied combinations of plant functional traits (i.e., the conception and development of multispecies/cultivar ideotype) and takes into account species/cultivar assemblies associated with plant adaptation to various stresses (both abiotic and biotic) may have a strong potential to promote IPM breeding. ${ }^{35}$

The first projects addressing the combination of phenotyping with breeding for crop diversity are underway. ${ }^{27}$ This type of selection requires research to be conducted in a diversity of environments. Experiments on the effects of varying environments compared to more constant environments on wheat composite cross populations indicate that populations exposed to variable environments over 5 years performed remarkably stable in two very contrasting years. ${ }^{37-39}$ Traits that are difficult to assess (e.g. root systems, association with microorganisms) will come more into focus as they play an important role for crop adaptation in a given environment.

To ensure the success of multiple trait-based breeding, breeders, farmers, crop physiologists and plant pathologists need to work together in testing the viability/validity of the trait-based approaches for resistance or tolerance to biotic and abiotic stresses. Detailed screenings using, where possible, modern high throughput phenotyping technology - e.g. for root systems ${ }^{40}$ but also simple laboratory techniques ${ }^{8}$ or associated microorganisms ${ }^{41}$ - are needed in addition to detailed field testing.

Certain traits have a strong potential for IPM. For example, plant architecture can play an important role to reduce pest impacts. ${ }^{42,43}$ However, standard breeding practices limit potential benefits that could be obtained by the presence of variable traits within a given 
field and/or landscape. Overall, erect plant varieties are preferred by standard breeding programs to improve light use efficiency, and reduce competition between plants, which goes against the need to manage weeds as it also decreases crop competitiveness with weeds. A mixture of architectures, in contrast, may increase shading of weeds. In addition, diversity in architecture can reduce relative humidity in the canopy due to better aeration and thus reduce certain diseases. ${ }^{44}$ Below ground interactions of variable root systems may contribute to weed control but also affect soil-borne diseases. ${ }^{45,46}$ Such results could pave the way to encourage the development of trait-based breeding approach thereby promoting IPM.

\section{Conclusions}

To date, all breeding technologies have been integrated under the same uniformity paradigm (i.e. development of the crop genotype performing in the best and dominant cropping system), to maximize market success. Plant breeding has resulted in numerous improved crop varieties in recent decades and, overall, traditional breeding (e.g. crossing, selection) remains an important activity for crop improvement.

Breeding for IPM may benefit from breeding approaches adopted for both conventional and organic farming. However, a specific focus for IPM is needed when breeding plant varieties, including innovative diversified populations that can be used for crop diversification through rotation, intercropping and mixed-cropping. Trait-based breeding approaches have a key role to play to boost IPM uptake. Plant varieties bred for IPM have to go through multi-field location testing, a common practice in many large breeding programs. This will enable selection and adaptation for regional and site-specific conditions resulting in greater varietal diversity and increase resilience of cropping systems to abiotic and biotic stresses. Besides adjustments in breeding methods, there 
will be a need for legal changes to the DUS paradigm if such breeding approaches have to be adopted in practical future breeding programs.

Overall, breeding for IPM evoked here involves creating greater crop diversity, and more focus on locally adapted crop cultivars. The stated aim is to generate sustainable and adaptable cropping systems, and to reduce reliance on conventional pesticides. While such objectives are often also part of commercial breeding programs, the market driven practice largely neutralizes these efforts. However, for sustainable agriculture and IPM managed cropping systems these have a much higher significance for breeders, farmers and consumers to provide them safe and secure food. With the limited number of respondents to our questionnaire from nineteen countries, most likely components of IPM are not mentioned or covered in this paper that will also be important for successful IPM systems. Nevertheless, the recommendations made here, addressed to all stakeholders involved in breeding programs, should help in refocusing breeding efforts for future farming systems.

\section{Acknowledgements}

The authors thank Stephen N. Wegulo and four anonymous reviewers for their useful comments on the earlier version of the manuscript and all participants of the workshop for their active and valuable contribution to the discussion, as well as those who did not attend but provided feedback on the questionnaire. The ERA-Net C-IPM is funded by the EU under the 7th framework programme (Grant agreement number 618110). 


\section{References}

1. Lamichhane JR, Dachbrodt-Saaydeh S, Kudsk P, Messéan A, Toward a reduced reliance on conventional pesticides in European agriculture. Plant Dis 100:10-24 (2016).

2. Barzman M, Bàrberi P, Birch ANE, Boonekamp P, Dachbrodt-Saaydeh S, Graf G et al., Eight principles of Integrated Pest Management. Agron Sustain Dev 35:1199-215 (2015).

3. Döring TF, Vieweger A, Pautasso M, Vaarst M, Finckh MR, Wolfe, MS, Resilience as a universal criterion of health. J Sci Food Agric 95: 455-465 (2015).

4. Desclaux D, Nolot JM, Chiffoleau Y, Gozé E, Leclerc C, Changes in the concept of genotype $\mathrm{x}$ environment interactions to fit agriculture diversification and decentralized participatory plant breeding: pluridisciplinary point of view. Euphytica 163: 533-546 (2008).

5. Brumlop S, Reichenbecher W, Tappeser B, Finckh MR, What is the SMARTest way to breed plants and increase agrobiodiversity? Euphytica 194:53-66 (2013).

6. Barot S, Allard V, Cantarel A, Enjalbert J, Gauffreteau A, Goldringer I, Lata J-C, Le Roux $\mathrm{X}$, Niboyet A, Porcher E, Designing mixtures of varieties for multifunctional agriculture with the help of ecology. A review. Agron Sustain Dev 37 (2017).

7. Dawson JC, Rivière P, Berthellot J-F, Mercier F, Kochko P de, Galic N et al., Collaborative Plant Breeding for Organic Agricultural Systems in Developed Countries. Sustainability 3:1206 (2011).

8. Bertholdsson NO, Weedon 0, Brumlop S, Finckh MR, Evolutionary changes of weed competitive traits in winter wheat composite cross populations in organic and conventional farming systems. Eur J Agron 79:23-30 (2016).

9. Lammerts van Bueren ET, Backes G, de Vriend H, Østergård H, The role of molecular markers and marker assisted selection in breeding for organic agriculture. Euphytica 175:51-64 (2010).

10. Finckh MR, Wolfe MS, Biodiversity enhancement. In: Finckh MR, van Bruggen AHC, Tamm L, editors. Plant Diseases and their Management in Organic Agriculture. St Paul, MN: APS Press; p. 153-174 (2015).

11. Mesterházy Á, Tóth B, Varga M, Bartók T,, Szabó-Hevér Á, Farády L, Lehoczki-Krsjak S, Role of Fungicides, of Nozzle Types, and the Resistance Level of Wheat Varieties in the Control of Fusarium Head Blight and Deoxynivalenol. Toxins 3: 1453-1483 (2011).

12. Ceccarelli S, Grando S, Decentralized-participatory plant breeding: an example of demand driven research. Euphytica 155:349-60 (2007).

13. Sperling L, Ashby JA, Smith ME, Weltzien E, McGuire SA, Framework for analyzing participatory plant breeding approaches and results. Euphytica. 122:439-50 (2001).

14. Wolfe MS, Baresel JP, Desclaux D, Goldringer I, Hoad S, Developments in breeding cereals for organic agriculture. Euphytica.163: 323 (2008). 
15. OSCAR. Optimizing Subsidiary Crop Applications in Rotations, Final report. 39 p..Available from: http://cordis.europa.eu/docs/results/289/289277/final1-finalreport-complete.pdf [13 June 2017].

16. Prieto I, Violle C, Barre P, Durand J-L, Ghesquiere M, Litrico I, Complementary effects of species and genetic diversity on productivity and stability of sown grasslands. Nat Plants. 30:15033 (2015).

17. Döring TF, Knapp S, Kovacs G, Murphy K, Wolfe MS, Evolutionary Plant Breeding in Cereals-Into a New Era. Sustainability 3:1944 (2011).

18. Khoury CK, Bjorkman AD, Dempewolf H, Ramirez-Villegas J, Guarino L, Jarvis A et al., Increasing homogeneity in global food supplies and the implications for food security. Proc Natl Acad Sci 111:4001-4006 (2014).

19. Wolfe MS, Döring TF, The increasing need for an agroecological approach to wheat breeding. In: Bonjean AP, Angus WJ, Van Ginkel M, editors. World Wheat Book. Lavoisier, France p. 845-72 (2016).

20. Brisson N, Gate P, Gouache D, Charmet G, Oury F-X, Huard F, Why are wheat yields stagnating in Europe? A comprehensive data analysis for France. Field Crop Res 119:20112 (2010).

21. Marshall DR, The advantages and hazards of genetic homogeneity. Ann N Y Acad Sci 287:1-20 (1977).

22. Kiyosawa $S$ Breakdown of blast resistance in relation to general strategies of resistance gene deployment to prolong effectiveness of resistance in plants. In: Leonard KJ, Fry WE, editors. Plant Disease Epidemiology. McGraw-Hill, New York p. 251-283 (1989).

23. Brown JKM. Surveys of variation in pathogen populations and their application to disease control. In: Jones DG, editor. The Epidemiology of Plant Diseases. Dordrecht, Boston, London: Kluwer Academic Publishers p. 73-102 (1998).

24. Phillips SL, Wolfe MS, Evolutionary plant breeding for low input systems. J Agric Sci143:245-254 (2005).

25. Newton AC, Begg GS, Swanston JS Deployment of diversity for enhanced crop function. Ann Appl Biol154:309-22 (2009).

26. Skelsey P, Rossing WAH, Kessel GJT, Powell J, van der Werf W, Influence of host diversity on development of epidemics: An evaluation and elaboration of mixture theory. Phytopathology95:328-38 (2005).

27. Ostergaard H, Finckh MR, Fontaine L, Goldringer I, Hoad SP, Kristensen K et al., Time for a shift in crop production: embracing complexity through diversity at all levels. J Sci Food Agric 89:1439-45 (2009).

28. Messéan A, Lamichhane JR, Menard J-M, Role of crop diversification to boost IPM and implications for breeding. In: Lamichhane JR, Arseniuk E, Messéan A, editors. Breeding for IPM in sustainable and low-input agricultural systems. Radzików, Poland;. p. 6 (2016).

29. Baresel JP, Backes G, Bülow L, Finckh MR, Frese L, Knapp S et al. Innovative approaches to optimize genetic diversity for sustainable farming systems of the future (INSUSFAR) - 
Project presentation. In: Kölliker R, Boller B, editors. Plant Breeding: the Art of Brining Science to Life Abstracts of the 20th EUCARPIA General Congress 29 Aug- 1 Sep 2016 Zürich, Switzerland. Zürich: Agroscope;. p. 42 (2016). Available from: http://eucarpia2016.org/images/docs/Eucarpia2016 AbstractsFinal.pdf $\quad[23$ June 2017].

30. Finckh MR, Gacek ES, Goyeau H, Lannou C, Merz U, Mundt CC et al. Cereal variety and species mixtures in practice, with emphasis on disease resistance. Agronomie 20:813-37 (2000).

31. Weedon 0, Finckh MR Yield stability in winter wheat composite cross populations under organic and conventional conditions from the F5 to the F13. COBRA Coordinating Organic plant Breeding Activities - for diversity Program and abstracts for the COBRA Final Conference 24th and 25th November 2015 at Vingsted hotel \& conference centre, Denmark [Internet]. Vingsted, Denmark;. p. 71-2 (2015). Available from: http://www.cobra-div.eu/cobra-conference-24th-november/ [27 June 2017].

32. Weedon 0, Brumlop S, Heinrich S, Finckh MR, Yield stability analysis for three winter wheat composite cross populations under organic and conventional management over five years. In: Kölliker R, Boller B, editors. Plant Breeding: the Art of Brining Science to Life Abstracts of the 20th EUCARPIA General Congress 29 Aug- 1 Sep 2016 Zürich, Switzerland. Zürich: Agroscope p. 193 (2016). Available from: http://eucarpia2016.org/images/docs/Eucarpia2016 AbstractsFinal.pdf [23 May 2017].

33. Khan ZR, Ampong-Nyarko K, Chiliswa P, Hassanali A, Kimani S, Lwande W et al., Intercropping increases parasitism of pests. Nature 388:631-632 (1997).

34. Enjalbert J, Borg J, Forst E, Gauffreteau A, Goldringer I, New challenges for breeding varieties adapted to mixed cropping systems. In: Lamichhane JR, Arseniuk E, Messéan A, editors. Breeding for IPM in sustainable and low-input agricultural systems. Radzików, Poland p. 30 (2016).

35. Gaba S, Lescourret F, Boudsocq S, Enjalbert J, Hinsinger P, Journet E-P et al., Multiple cropping systems as drivers for providing multiple ecosystem services: from concepts to design. Agron Sustain Dev 35:607-23 (2015).

36. Crespo-Herrera LA, Ortiz R, Plant breeding for organic agriculture: something new? Agric Food Secur 4:1-7 (2015).

37. Döring TF, Annicchiarico P, Clarke S, Haigh Z, Jones HE, Pearce H et al., Comparative analysis of performance and stability among composite cross populations, variety mixtures and pure lines of winter wheat in organic and conventional cropping systems. Field Crop Res 183:235-45 (2015).

38. Weedon O, Haak A, Brumlop S, Heinrich S, Finckh MR, The effect of changing environmental conditions on composite cross winter wheat populations over six years from the F8 to the F14. COBRA Coordinating Organic plant BReeding Activities - for diversity Program and abstracts for the COBRA Final Conference 24th and 25th November 2015 at Vingsted hotel \& conferencecentre, Denmark. Vingsted, Denmark p. 73-4 (2015). Available from: http://www.cobra-div.eu/cobra-conference-24th-november/ [23 May 2017].

39. Weedon 0, Brumlop S, Heinrich S, Boening A, Elsner M, Finckh MR et al., Agronomic performance of two generations (F12 and F13) of thirteen winter wheat composite cross 
wheat populations with differing cultivation histories in 2014/15. In: Kölliker R, Boller B, editors. Plant Breeding: the Art of Brining Science to Life Abstracts of the 20th EUCARPIA General Congress 29 Aug- 1 Sep 2016 Zürich, Switzerland. Zürich: Agroscope p. 192 (2016). Available from: http://eucarpia2016.org/images/docs/Eucarpia2016 AbstractsFinal.pdf $\quad[16$ June 2017].

40. Paez-Garcia A, Mtes CM, Scheible W-R, Chen R, Blancaflor EB, Monteros MJ, Root traits and phenotyping strategies for plant improvement. Plants 4:334-55 (2015).

41. Pérez-Jaramillo JE, Mendes R, Raaijmakers JM, Impact of plant domestication on rhizosphere microbiome assembly and functions. Plant Mol Biol90:635-44 (2016).

42. Le May C, Ney B, Lemarchand E, Schoeny A, Tivoli B, Effect of pea plant architecture on spatiotemporal epidemic development of ascochyta blight (Mycosphaerella pinodes) in the field. Plant Pathol 58:332-43 (2009).

43. Tivoli B, Calonnec A, Richard B, Ney B, Andrivon D, Current knowledge on plant/canopy architectural traits that reduce the expression and development of epidemics. Eur J Plant Pathol 135:471-8 (2013).

44. Zhu Y, Fang H, Wang Y, Fan JX, Yang S, Mew TW et al., Panicle blast and canopy moisture in rice cultivar mixtures. Phytopathology 95:433-8 (2005).

45. Friebe A, Vilich V, Henning L, Kluge M, Sicker D, Detoxification of Benzoxazolinone allelochemicals from wheat by Gaeumannomyces graminis var. graminis, G. graminis var. avenae, and Fusarium culmorum. Appl Environ Microbiol64:2386-91 (1998).

46. Yang M, Zhang Y, Qi L, Mei X, Liao J, Ding X et al., Plant-plant-microbe mechanisms involved in soil-borne disease suppression on a maize and pepper intercropping system. PLoS One e115052:1-22 (2014).

47. Finckh MR, Tamm L, Organic management and airborne diseases. Plant diseases and their management in organic agriculture. In: Finckh MR, van Bruggen AHC, Tamm L (eds). St. Paul, MN, APS Press: 53-66. (2015).

48. Datnoff LE, Elmer, WH, Huber DM (eds), Mineral nutrition and plant disease. The American Phytopathological Society, St. Paul, Minnesota, U. S. A. 278 pp. (2007).

49. Döring TF, Pautasso M, Wolfe MS, Finckh MR, Pest and disease management in organic farming: Implications and inspirations for plant breeding. Organic Crop Breeding. E. T. Lammerts van Bueren and L. D. Myers. Chichester, UK, Wiley-Blackwell: 39-60 (2012).

50. de Milliano WAJ, Lammerts van Bueren ET, Voorrips RE, Myers JR, Resistance and resistance breeding for organic farming. Plant disease management in organic agriculture. In: Finckh MR, van Bruggen AHC, Tamm L (eds). St. Paul, MN, APS Press: 175-187 (2015). 
Box 1. Key differences between organic and IPM farming systems

\section{Organic farming}

- Plant nutrition is a limiting factor because highly soluble mineral fertilizers are not allowed thereby changing disease dynamics (e.g. for some pathosystems, a plant with stunted growth has higher possibility of pathogen attacks than a plant in good growing shape). ${ }^{47,48}$

- The use of conventional (inorganic) pesticides is forbidden to manage epidemics. Growers have to rely on preventive measures or where available select nonsynthetic/organic pesticides.

- An incorrect decision concerning cropping practices (e.g. sowing date, plant density, inadequate cropping sequence) in most cases may not be easily corrected by using inorganic pesticides in case of epidemic development.

\section{Integrated Pest Management}

- Plant nutrition is not usually limiting as the judicious use of mineral fertilizers is allowed to improve crop growth.

- Conventional pesticides can be used to manage epidemics, although as the last option.

- If a wrong decision is made on cropping practices (e.g. sowing date or sequence, plant density), often, the error can be corrected by using inorganic pesticides. However, this could be also a drawback for IPM since, in such a case, chemical tools - which are generally used as a last option in IPM - may prevail over the nonchemical one. 
Table 1. Relevant questions and multiple answers related to breeding for IPM asked through the questionnaire. The same respondent could provide more than one answer to the same question. In total, thirty-nine experts responded to the questionnaire.

\section{Question \\ 1. What is breeding for IPM?}

No. of Responses ${ }^{1}$ Percentage $^{2}$

Breeding targeting on sustainable pest and disease resistance

Breeding programs designed for organic/low-input farming or other more resilient farming systems

It is about to combine/adapt breeding strategies with other agronomic practices

Breeding whose targets are selected to facilitate implementation of IPM

27

27

14

69

\section{Are there current R\&D programs in Europe for breeding for IPM?}

Yes, there are

No, there are not

I don't know

$\begin{array}{cc}21 & 54 \\ 7 & 18 \\ 11 & 28 \\ & \\ 23 & 59 \\ 6 & 15 \\ 10 & 26 \\ & \\ 17 & 44 \\ 11 & 28 \\ 17 & 44 \\ 22 & 56 \\ 26 & 67 \\ & \\ 34 & 87 \\ 15 & 38 \\ 22 & 56\end{array}$

\section{For breeding for IPM, are there current R\&D programs in your country?}

Yes, there are

No, there are not

I don't know

\section{How can we promote "breeding for IPM" at the European level?}

Developing new breeding technologies as they are more prone to support IPM

Changing the targets of existing technologies to facilitate IPM

Developing specific varieties for specific pedo-climatic conditions (adaptation to local contexts)

Co-design new variety development and IPM strategies

Bringing together more resistance mechanisms in one cultivar to avoid resistance breaking by the pathogen

5. How can existing breeding technologies be integrated in a wider IPM context?

Through improvements of crop agronomic traits together with pest resistance traits

By supporting breeding for minor crops so as to promote diversification of crops

Focusing on a better deployment strategies of existing partially resistant varieties

6. Which of the following takes higher priority in R\&D programs that focus on breeding for IPM? 
Modifying plants to reduce pest pressure over time

7. Which of the following takes higher priority in R\&D programs that focus on breeding for IPM?

Diseases

Animal pests (insects included)

Weeds

8. Which of the following takes higher priority in R\&D programs that focus on breeding for IPM?

Tolerance

Competitiveness at large to be part of diversification

Weeds

9. On which type of breeding for crop diversification shall we focus?

Intercropping (association, mixed crops)

1In total, 39 respondents provided their feedback to the questionnaire

${ }^{2}$ Calculated by the ratio between the number of responses obtained and the number of total respondents 
Table 2. Breeding for Integrated Pest Management targets and their current implementation status in relation to organic and low-input farming. While host genetic resistance to disease has been well implemented (in green), other IPM leverages such as crop rotation and cover crops are only partially deployed (in yellow) to manage crop pests. The majority of IPM leverages still suffer from a complete lack of adoption (in red). Unlike breeding for IPM, several previous works have clearly highlighted ongoing programs and future directions for organic breeding. ${ }^{49,50}$

\begin{tabular}{|c|c|c|c|c|c|}
\hline IPM tools & Biological/technical leverage & Breeding target (ex. of traits) & \multicolumn{3}{|c|}{$\begin{array}{c}\text { Current implementation status in breeding } \\
\text { programs }\end{array}$} \\
\hline \multirow[b]{3}{*}{ Biological } & Host genetic resistance to diseases & $\begin{array}{l}\text { Disease/Pest resistant varieties (e.g. major } \\
\text { race-specific R-genes and/or quantitative } \\
\text { resistance) }\end{array}$ & $\begin{array}{l}\text { Done but } \\
\text { resistance to seed- } \\
\text { borne pests } \\
\text { largely missing }\end{array}$ & $\begin{array}{l}\text { Some work } \\
\text { done on } \\
\text { resistance } \\
\text { to seed- } \\
\text { borne pests }\end{array}$ & $\begin{array}{l}\text { Transfered } \\
\text { from } \\
\text { conventional }\end{array}$ \\
\hline & $\begin{array}{l}\text { Better R-gene deployment on } \\
\text { landscape }\end{array}$ & $\begin{array}{l}\text { Integration of R-gene rotation strategy in } \\
\text { breeding schemes }\end{array}$ & Largely absent & Absent & Absent \\
\hline & $\begin{array}{l}\text { Breeding for intraspecific diversity } \\
\text { (Within-species and within-field } \\
\text { diversification) }\end{array}$ & $\begin{array}{l}\text { Synthetic cultivars: } \\
\text { Breeding for segregating and highly diverse } \\
\text { populations for genes and mechanisms of } \\
\text { pest resistance and tolerance }\end{array}$ & Absent & Absent & Absent \\
\hline
\end{tabular}

This article is protected by copyright. All rights reserved document

Lamichhane, J. R. (Auteur de correspondance), Arseniuk, E., Boonekamp, P., Czembor, J., 


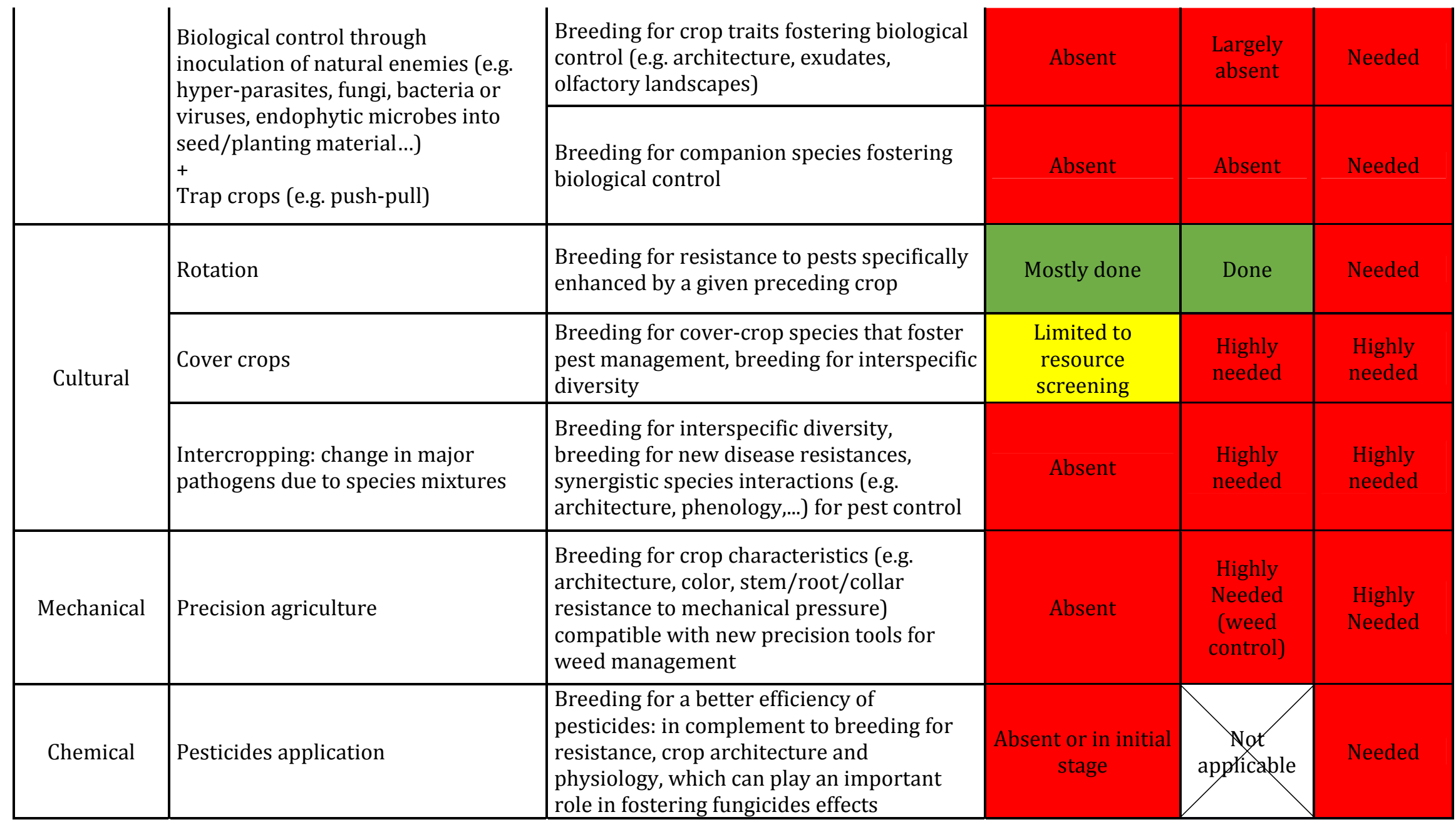

